\title{
Multi-Parameter Approach for Evaluation of Genomic Instability in the Polycystic Ovary Syndrome
}

\author{
Nishu Sekar ${ }^{1}$, Manju Nair ${ }^{1}$, Glory Francis ${ }^{1}$, Parvathy Raj Kongath ${ }^{1}$, Sandhya \\ Babu $^{2}$, Sudhakaran Raja ${ }^{1}$, Abilash Valsala Gopalakrishnan ${ }^{1 *}$
}

\begin{abstract}
Background: The polycystic ovary syndrome (PCOS), characterized by hyperandrogenism and chronic anovulation, is a common endocrine disorder in women. PCOS, which is associated with polycystic ovaries, hirsutism, obesity and insulin resistance, is a leading cause of female infertility. In this condition there is an imbalance in female sex hormones. All the sequelae symptoms of PCOS gradually lead to cancer in the course of time. It is heterogeneous disorder of unknown etiology so it is essential to find the exact cause. Materials and Methods: In this study both invasive and non-invasive techniques were employed to establish the etiology. Diagnosis was based on Rotterdam criteria (hyperandrogenism, ovulatory dysfunction, PCOM) and multiparameters using buccal samples and dermatoglypic analysis and cytogenetic study for 10 cases and four age and sex matched controls. Results: In clinical analysis we have observed the mean value of total testosterone level was $23.6 \mathrm{nmol} / \mathrm{L}$, total hirsutism score was from 12-24, facial acne was found in in 70\% patients with 7-12 subcapsular follicular cysts, each measuring $2-8 \mathrm{~mm}$ in diameter. In dermatoglypic analysis we observed increases in mean value $\left(45.9^{\circ}\right)$ of ATD angle when compared with control group and also found increased frequency (38\%) of Ulnar loops on both fingers (UU), (18\%) whorls on the right finger and Ulnar loop on left finger (WU) and (16\%) arches on right and left fingers (AA) were observed in PCOS patients when compared with control subjects. Features which could be applied as markers for PCOS patients are the presence of Ulnar loops in middle and little fingers of right and left hand. The buccal micronucleus cytome assay in exfoliated buccal cells, we found decrease in frequency of micronuclei and significant increases in frequency of karyolysed nuclei in polycystic ovarian syndrome patients. Chromosome aberration analysis revealed a significant increase in frequency of chromosome aberrations (CAs) in PCOS patients when compared with controls. Conclusions: From this present work it can be concluded that non-invasive technique like dermatoglypics analysis and buccal micronucleus cytome assays with exfoliated buccal cell can also be effective biomarkers for PCOS, along with increased CAs in lymphocytes as a sign of genetic instability. There is a hypothesis that micronuclei and chromosomal aberrations could have a predictive value for cancer. From this present work it can be concluded to some extent that non-invasive technique like dermatoglypics and buccal cell analysis can also be effective for diagnosis.
\end{abstract}

Keywords: Polycystic ovary syndrome - cytogenetic - dermatoglypics - buccal micronuclei analysis

Asian Pac J Cancer Prev, 16 (16), 7129-7138

\section{Introduction}

Polycystic ovary syndrome (PCOS) is a complex and heterogeneous disorder, affecting approximately $7 \%$ of women in reproductive age (Diamant Kandarakis, 2008). It is distinguished by chronic anovulation, hyperandrogenemia, altered $\mathrm{LH}$ : FSH ratio $(>2 / 3: 1)$ and polycystic ovaries. The syndrome is a major cause of anovulatory infertility (Dunaif et al., 1997).

The etiology and pathogenesis of this syndrome still remains mysterious but likely to be mutifactorial consisting of genetic and environmental components. Women with PCOS are frequently obese which contributes an extrinsic component of Insulin Resistance (IR). It is known that
IR progresses towards the development of compensatory hyperinsulinemia, which drives Hyperandrogenemia in these women (Poretsky et al., 1999). Increased production of androgen levels lead to menstrual disturbances, development of ovarian cysts, facial acne, Hirsutism and other related disorders. The diverse nature of its clinical and biochemical features, it has been suggested that PCOS represents a range of disorders rather than a single entity (Simpson et al., 1992). Although it seems likely that there is more than one cause of this disorder, there are certain biochemical features which are common to all groups of subjects with ultrasonographic evidence of polycystic ovaries irrespective of the clinical appearance. Clustering of cases in families strongly support the role of 
Nishu Sekar et al

genetic factors in the development of polycystic ovarian syndrome, heterogeneity of physical features in different families and even within the same family underscores the importance of the environmental contribution. Whereas several positive results have been reported, there is no candidate gene universally accepted and fundamentally important in PCOS aetiology. This has resulted partially because of a mixture of factors such as the lack of a worldwide accepted diagnostic scheme for PCOS, diagnostic capability only in Reproductiveaged women, limited number of patients in case-control studies, analysis of only one or two variants of candidate genes and incomplete knowledge of pathophysiology and etiology of the syndrome. Now PCOS has recently been linked with genomic instability and DNA damage. Genomic instability refers to a variety of DNA alterations. Chromosomal instability (CIN) is the most prevalent form of genomic instability and leads to changes in both chromosome number and structure (Lengauer et al., 1998). It is still unclear that the state of hyperandrogenism of PCOS patients is directly associated with endometrial hyperplasia (Zhao et al., 2014). The aim of our study is to test Genomic damage in women PCOS, using multiple parameters with different methods for assessing damage in chromosomal level. The parameters include chromosome aberration analysis, Buccal Micronucleus Cytome (BMCyt) Assay and Dermatoglypics study. The Buccal Micronucleus Cytome (BMCyt) assay is a new minimally invasive system for studying DNA damage, chromosomal instability, cell death, and the regenerative potential of Buccal mucosal tissue. This method is increasingly being used in molecular epidemiologic studies investigating the impact of nutrition, life-style factors, Genotoxin exposure, and Genotype on DNA damage and cell death. Biomarkers of this assay have been associated with increased risk for accelerated aging; cancer, and neurodegenerative diseases .Clinical Dermatoglyphics is a science that studies dermal patterns (Dermatoglyphs) on the volar side of hands and soles. Dermal ridge differentiation takes place early in fetal development. The resulting ridge configurations are genetically determined and influenced or modified by environmental factors (Schaumann and Alter, 1976). They are stable throughout life, unique to the individual, and significant as a means of identification. DG is in use as a diagnostic tool in genetic/ chromosomal disorders as well as in clinical conditions with genetic etiology. Dermatoglyphs are unique for each person; therefore studying of Dermatoglyphcs in patients can determine with number of parameters which could be helpful in diagnosing and treatment of various disorders. Amenorrhoea and Dermatoglyphic patterns both have multifactorial determinants which can be broadly categorized as genetic and environmental (Meenakshi et al., 2006). In the light of this background the present study is conducted to estimate the genomic instability of PCOS to shed light on some techniques including clinical, Dermatoglypics, exfoliated Buccal cell Micronuclei assay and chromosome analysis with PCOS to reach some aspects of its pathogenesis through a comparison with normal women as control.

\section{Materials and Methods}

\section{Collection of samples}

A total number of 10 cases of buccal samples, dermatoglyphics and blood samples from PCOS patients aged between 18 to 28 years have been collected from Sandhya Hospital, Vellore. Detailed information about the family history of each affected individual was recorded in a standard proforma. Epidemiological studies for these cases were done and their clinical records including Hirsutism, Acne, Irregular period, obesity, diabetics, cardio problem, Acanthosis Nigricans and Ovarian morphology were recorded. Hirsutism scoring was recorded according to Ferrimen Gallway scoring system (Ferriman and Gallwey, 1961). This tool is used to evaluate hair growth at seven sites: upper lip, chin/ face, chest, back, abdomen, arms, and thighs. A score of 0 is given in the absence of terminal hair growth and a score of 4 is given for extensive growth. A total score of 8 or more is indicative of Hirsutism (Unluhizarci K., 2012). Blood collection was done by venipuncture and the blood was collected in sterile vacutainers (Heparin \& EDTA). Buccal samples, Dermatoglyphics and blood samples were collected from $(n=04)$ from control normal individuals simultaneously. Informed consent was taken from all individuals included in this study. The study was approved by the University Human Ethical Committee of the VIT University

\section{Dermatoglyphics analysis}

Dermatoglyphics samples were taken for 10 cases of PCOS and 4 control samples by touch the ink with finger on its side and roll smoothly across the ink 180 degree to the opposite side of the finger and lift. Repeat the motion on paper, transferring the print. Palm prints require a similar procedure. the palm needs to be slowly rolled to transfer the edge (Cummins Midlo, 1943). Remove ink from hands with soap and water. The Dermatoglyphic patterns were recorded and parameters like fingertip patterns (ulnar loops, radial loops, whorls, arches) and "a-t-d" angle were studied.

\section{Buccal micronucleus cytome (BMCyt) assay}

Buccal Cell Sampling and Preparation: Buccal cells (BCs) were collected from 10 clinically confirmed cases of PCOS patients from Sandya Hospital, Vellore and 4 control subjects were carried out. Prior to Buccal cell collection the mouth was rinsed thoroughly with water to remove any unwanted debris. Buccal cell samples were obtained by rubbing the inside of both cheeks using a cyto brush.

\section{Buccal micronucleus cytome (BMCyt) assay}

The BMCyt assay test was carried out on Buccal epithelial cells of 10 clinically confirmed cases of PCOS and 4 controls subjects. Oral Buccal cells obtained were smeared on a pre-cleaned slide, fixed in methanol and stained with $4 \%$ Giemsa. A total of 500 cells per individual were scored for analysis of micronuclei.

Scoring criteria for micro nuclei assay: For the 
Micronuclei analysis, 500 Buccal cells were evaluated per subject according to the criteria established by (Nina et al., 2008) under a microscope at 100X magnifications to identify Binucleated cells, Micronuclei, Nuclear Buds and Fragmented Nucleus.

Statistical Analysis: The samples were coded at the time of preparation and scoring. They were decoded before statistical analysis for comparison. Mean and standard deviation (SD) were calculated for biomarkers. Mean values and standard deviations were computed for the scores and the statistical significance $(\mathrm{P}<0.001)$.

\section{Cytogenetic analysis}

Chromosome Preparation: Chromosome preparations were obtained from Phytohaemagglutinin-stimulated peripheral blood lymphocytes (Hungerford, 1965). About $2 \mathrm{ml}$ of venous blood sample was collected from each PCOS patients and control subjects in sterile Heparinized syringes. $0.5 \mathrm{ml}$ of the blood was inoculated into the vials containing $5 \mathrm{ml}$ of Ready mix RPMI 1640 medium containing $1 \mathrm{ml}$ of Fetal Bovine Serum (FBS) and $0.2 \mathrm{ml}$ of Phytohaemagglutinin under aseptic condition. The culture vials were then placed in an incubator at $37^{\circ} \mathrm{C}$. The cultures were shaken every 24th hour and carbon dioxide was released once in 24 hours. At the 72 nd hour harvested the culture. At the end of the incubation period (72nd hour), the dividing cells were arrested at metaphase by adding 2 drops of $0.1 \%$ Colchicine solution to each culture vial. The cultures were incubated further for 20 minutes at $37^{\circ} \mathrm{C}$, (Hungerford et.al 1965). Lymphocytes were harvested after 20 min by centrifuging cell suspension to remove culture medium (2000 rpm), addition of Hypotonic solution $(\mathrm{KCl} 0.075 \mathrm{M})$ at $37^{\circ} \mathrm{C}$ for 6-7 min to swell the cells, and treated twice with Carnoy's fixative (3:1 ratio of methanol: acetic acid). Slides were carefully dried on a hot plate $\left(40^{\circ} \mathrm{C}\right)$. Later, the slides were stained and banded with Giemsa stain.

Slide preparation: The cell button was suspended in a small quantity of freshly prepared fixative. A test slide was prepared by gently placing a drop of the cell suspension on a cleaned glass slide and dried immediately on a hot plate (400C).The test slide was examined under the microscope for cell density and metaphase spreads. Other slides were prepared after suitable modifications.

Staining procedure: The slides were stained in $4 \%$ Giemsa solution for 4 minutes and destained in double distilled water for 2 minutes.

Scoring: A minimum of 50 technically good metaphase plates of each sample was analyzed. Scoring of chromosomal aberrations including chromatid and chromosomal breaks and deletions were carried out in well spread and stained cells under oil immersion objective lens (100X) of the light microscope (Magnus MPX) to identify numerical and structural Chromosomal aberrations.

Giemsa Banding: 2-3 days old slide with good metaphase spreads were taken. The slides were treated with $0.0125 \%$ freshly prepared trypsin solution for 4-5 seconds and rinsed with double distilled water. The above treated slides were stained using Giemsa stain for 4 minutes and were thoroughly air dried.

Microphotography: Well spread metaphases of
Giemsa stained and Giemsa banded spreads were selected and photographed under oil immersion objective lens (100X) of Leica DM2000 microscope with Metasystems camera and the photomicrographs of banded spreads were karyotyped using automatic IKaros software (Metasystems).

Statistical analysis: The samples were coded at the time of preparation and scoring. They were decoded before statistical analysis for comparison. Mean and standard deviation (SD) were calculated. The significance of the differences was found between control and PCOS. Mean values and standard deviations were computed for the scores and the statistical significance $(\mathrm{P}<0.001)$.

\section{Results}

\section{Clinical analysis}

This study is carried out with 10 PCOS patients with 4 Control samples with age between 18 to 28 years. Among the entire patient group we have observed that they have irregular periods and $70 \%$ patients having facial acne but we did not observe any insulin resistance, Cardio or Acanthosis Nigricans symptoms. In this study we have observed the range of total Hirsutism score from 12-24 and mean value of total testosterone level was $23.6 \mathrm{nmol} / \mathrm{L}$. Among the patient group some females have been suffering from PCOS from long term and we found that one of the female has age of onset of irregular periods from of 13 years (Table 1A). In our study we have observed 7-12 Subcapsular follicular cysts; each measure $2-8 \mathrm{~mm}$ in diameter. Ovarian morphology was recorded and presented in Table1B.

\section{Dermatoglyphics analysis}

Dermatoglyphics analyses were carried out for all the 10 cases of PCOS and 4 control subjects. The Dermatoglyphics patterns observed in right and left hands of controls and PCOS patients were presented in Table 2A. The frequency of inheritance patterns observed in controls and PCOS patients were presented in Table 2B. The Dermatoglyphics illustrations were presented in Figure1. In this study we have observed that mean value of ATD angle of right and left hand of control is $41.87^{\circ}$ and for PCOS patient is $45.95^{\circ}$ and it conclude that PCOS patients have the elevated ATD angle when compare with control group (Figure 1). The inheritance pattern type observed in PCOS patients are $3(30 \%)$ dominant type inheritance and 7 (70\%) semi dominant type of inheritance and for control are $1(25 \%)$ of them are dominant inheritance and 3(75\%) semi dominat type inheritance. Increased frequency of inheritance pattern observed in PCOS patients are 19 (38\%) Ulnar loops on both fingers (UU)=Semidominant type of inheritance, 9 (18\%) Whorls on right finger and Ulnar loop on left finger $(\mathrm{WU})=$ Dominant type of inheritance and $8(16 \%)$ Arches on right and left finger $(\mathrm{AA})=$ Dominant type of inheritance and for controls are $6(30 \%)$ Whorls on right and left finger $(\mathrm{WW})=$ Semidominant type of inheritance, $4(20 \%)$ Ulnar loops on both fingers (UU)=Semidominant type of inheritance, $3(15 \%)$ Arches on left finger and Ulnar loops on right finger $(\mathrm{AU})=$ Dominant type of 


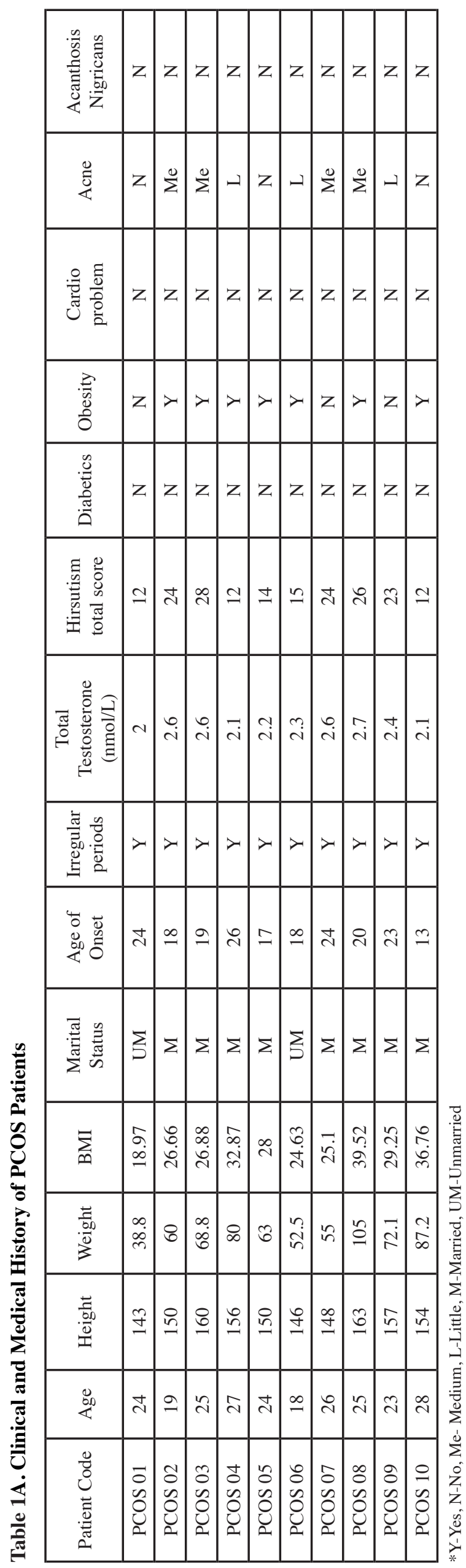

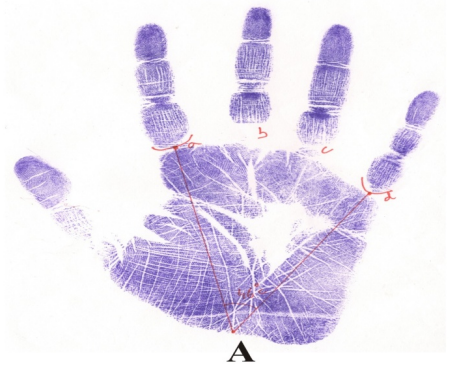

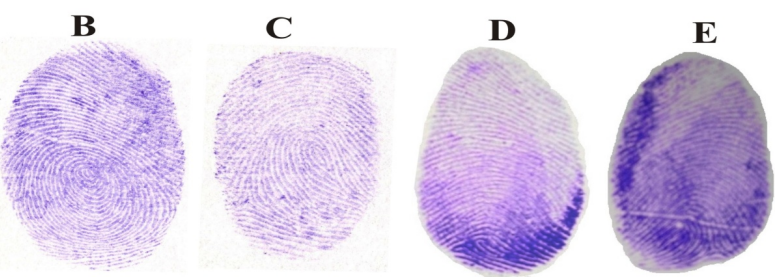

Figure 1. Scanned Image of Palm Print of the PCOS patient. A- represent the elevated ATD angle degree of PCOS patient; B-represent whorl pattern; C- represent ulnar loop pattern; D- represent arch pattern; E- represent radial loop pattern

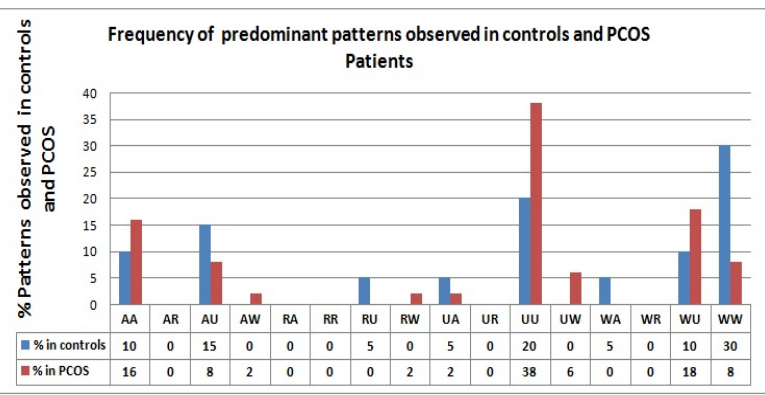

Figure 2. Bar Diagram Showing the Percentage of Dermatoglyphic Pattern Observed in Controls and PCOS Patients. AA: Arches Arches, AR: Arches Radial, AU: Arches Ulnar, AW: Arches Whorls, RA: Radial Arches, RR: Radial Radial, RU: Radial Ulnar, RW: Radial Whorls, UA: Ulnar Arches, UR: Ulnar Radial, UU: Ulnar Ulnar, UW: Ulnar Whorls, WA: Whorls Arches, WR: Whorls Radial, WU: Whorls Ulnar, WW: Whorls Whorls

inheritance. Percentage of predominant dermatoglyphic pattern observed in control and PCOS patients were presented in Figure 2.

\section{Buccal micronucleus cytome (BMCyt) assay}

Buccal Cell Analysis: Exfoliated Buccal cell micronuclei analysis was carried out in all the 10 PCSO patients and 4 age and sex matched control samples. The Buccal cell aberrations observed in PCOS patients and control samples in following frequencies. The percentage of Binucleated cells was found to be in $7.4 \%$ for PCOS patients and for control $9.25 \%$. The frequency of Binucleated cells per 500 cells was found to be significantly 1ower in PCOS patients than controls. [PCOS patient's (mean $\pm \mathrm{SD}$ ): $37 \pm 23.24$ versus controls $46 \pm 31.45$ ]. The percentage of micronuclei in cells was $0.10 \%$ in PCOS patient's and $0.25 \%$ in controls, the frequency of total number of micronuclei per 500 cells $($ mean $\pm \mathrm{SD})$ is $0.5 \pm 1.58$ in PCOS patient's and for controls it is $1.25 \pm 2.5$.

The percentage of Trinucleated cells was $1.10 \%$ in 
Multi-Parameter Approach for Evaluation of Genomic Instability in the Polycystic Ovary Syndrome Table 1B. Ovarian Morphology of PCOS Patients

\begin{tabular}{|c|c|c|c|c|c|c|}
\hline \multirow[t]{2}{*}{ Patient Code } & \multicolumn{2}{|c|}{ Ovary Measurement } & \multicolumn{2}{|c|}{ No of Follicles } & \multicolumn{2}{|c|}{ Size of Follicles } \\
\hline & Right $(\mathrm{cm})$ & $\operatorname{Left}(\mathrm{cm})$ & Right Ovary & Left Ovary & Right & Left \\
\hline$\overline{\mathrm{PCOS}} 01$ & $3.6 \times 2.0$ & $3.5 \times 2.0$ & 10 & 11 & $3 \mathrm{~mm}$ & $5 \mathrm{~mm}$ \\
\hline PCOS 02 & $2.1 \times 1.6$ & $2.5 \times 1.5$ & 10 & 10 & $4 \mathrm{~mm}$ & $4 \mathrm{~mm}$ \\
\hline PCOS 03 & $4.3 \times 3.2 \times 2.7$ & $3.7 \times 3.4 \times 2.9$ & 9 & 12 & $5 \mathrm{~mm}$ & $4 \mathrm{~mm}$ \\
\hline PCOS 04 & $2.8 \times 3.1 \times 2.7$ & $3.5 \times 2.7 \times 2.6$ & 12 & 11 & $4 \mathrm{~mm}$ & $6 \mathrm{~mm}$ \\
\hline PCOS 05 & $3.7 \times 2.8 \times 1.7$ & $4 \times 2.5 \times 2$ & 8 & 11 & $5 \mathrm{~mm}$ & $5 \mathrm{~mm}$ \\
\hline PCOS 06 & $4.0 \times 26.1$ & $4.41 \times 2.35$ & 9 & 10 & $3 \mathrm{~mm}$ & $3 \mathrm{~mm}$ \\
\hline PCOS 07 & $4.7 \times 2.5 \times 1.7$ & $4.2 \times 1.7 \times 2.5$ & 8 & 9 & $6 \mathrm{~mm}$ & $5 \mathrm{~mm}$ \\
\hline PCOS 08 & $3.5 \times 2.4$ & $3.1 \times 2$ & 10 & 12 & $5 \mathrm{~mm}$ & $5 \mathrm{~mm}$ \\
\hline PCOS 09 & $3.3 \times 2.8 \times 1.7$ & $4 \times 2.7 \times 2$ & 7 & 9 & $3 \mathrm{~mm}$ & $5 \mathrm{~mm}$ \\
\hline PCOS 10 & $4.5 \times 3.5 \times 2.9$ & $3.7 \times 3.1 \times 2.7$ & 11 & 13 & $4 \mathrm{~mm}$ & $4 \mathrm{~mm}$ \\
\hline
\end{tabular}

cm-Centimeter. mm-Millimeter

Table 2A. Dermatoglypics Pattern Observed in Right and Left Hand of Controls and PCOS Patients

\begin{tabular}{|c|c|c|c|c|c|c|c|c|c|}
\hline $\begin{array}{l}\text { Lab } \\
\text { Code }\end{array}$ & $\begin{array}{l}\text { Thumb } \\
\text { finger }\end{array}$ & $\begin{array}{l}\text { Index } \\
\text { finger }\end{array}$ & $\begin{array}{l}\text { Middle } \\
\text { finger }\end{array}$ & $\begin{array}{l}\text { Ring } \\
\text { finger }\end{array}$ & $\begin{array}{l}\text { Little } \\
\text { finger }\end{array}$ & $\begin{array}{l}\text { Inheritance } \\
\text { pattern }\end{array}$ & $\begin{array}{c}\text { Right } \\
\text { hand palm } \\
\text { angle }\end{array}$ & $\begin{array}{c}\text { Left hand } \\
\text { palm } \\
\text { angle }\end{array}$ & $\begin{array}{c}\text { Mean value of } \\
\text { right and left } \\
\text { palm angle }\end{array}$ \\
\hline CON01 & WW(SD) & UU(SD) & $\mathrm{AU}(\mathrm{D})$ & WW(SD) & $\mathrm{UU}(\mathrm{SD})$ & SD & 40 & 40 & 40 \\
\hline CON 02 & $\mathrm{AA}(\mathrm{D})$ & $\mathrm{AA}(\mathrm{D})$ & RU(RE) & $\mathrm{UU}(\mathrm{SD})$ & $\mathrm{UU}(\mathrm{SD})$ & SD & 43 & 42 & 42.5 \\
\hline CON 03 & $\mathrm{AU}(\mathrm{D})$ & UA(D) & $\mathrm{AU}(\mathrm{D})$ & WA(D) & WU(D) & $\mathrm{D}$ & 43 & 41 & 42 \\
\hline CON 04 & WW(SD) & $\mathrm{WW}(\mathrm{SD})$ & $\mathrm{WW}(\mathrm{SD})$ & WW(SD) & WU(D) & SD & 42 & 44 & 43 \\
\hline \multicolumn{6}{|c|}{ Mean Value } & & 42 & 41.75 & 41.87 \\
\hline PCOS 1 & WW(SD) & WU(SD) & WU(D) & WW(SD) & WU(D) & SD & 46 & 42 & 44 \\
\hline PCOS 2 & $\mathrm{AA}(\mathrm{D})$ & $\mathrm{AA}(\mathrm{D})$ & $\mathrm{AA}(\mathrm{D})$ & $\mathrm{AA}(\mathrm{D})$ & $\mathrm{AA}(\mathrm{D})$ & $\mathrm{D}$ & 46 & 47 & 46.5 \\
\hline PCOS 3 & $\mathrm{AA}(\mathrm{D})$ & $\mathrm{AU}(\mathrm{D})$ & $\mathrm{UU}(\mathrm{SD})$ & WU(D) & $\mathrm{UU}(\mathrm{SD})$ & D & 50 & 47 & 48.5 \\
\hline PCOS 4 & $\mathrm{UU}(\mathrm{SD})$ & WW(SD) & WU(D) & WU(D) & $\mathrm{UU}(\mathrm{SD})$ & SD & 46 & 44 & 45 \\
\hline PCOS 5 & $\mathrm{AU}(\mathrm{D})$ & $\mathrm{RW}(\mathrm{RE})$ & $\mathrm{UU}(\mathrm{SD})$ & $\mathrm{UU}(\mathrm{SD})$ & $\mathrm{UU}(\mathrm{SD})$ & SD & 54 & 48 & 51 \\
\hline PCOS 6 & UW(SD) & $\mathrm{UU}(\mathrm{SD})$ & $\mathrm{UU}(\mathrm{SD})$ & UW(SD) & $\mathrm{UU}(\mathrm{SD})$ & $\mathrm{SD}$ & 47 & 46 & 46.5 \\
\hline PCOS 7 & WW(SD) & WU(D) & UU(SD) & $\mathrm{WU}(\mathrm{D})$ & WU(D) & $\mathrm{D}$ & 47 & 47 & 47 \\
\hline PCOS 8 & $\mathrm{UU}(\mathrm{SD})$ & $\mathrm{UW}(\mathrm{SD})$ & $\mathrm{UU}(\mathrm{SD})$ & $\mathrm{AU}(\mathrm{D})$ & $\mathrm{AW}(\mathrm{D})$ & SD & 39 & 46 & 42.5 \\
\hline PCOS 9 & $\mathrm{AA}(\mathrm{D})$ & UA(D) & $\mathrm{UU}(\mathrm{SD})$ & $\mathrm{UU}(\mathrm{SD})$ & $\mathrm{UU}(\mathrm{SD})$ & SD & 42 & 47 & 44.5 \\
\hline PCOS 10 & $\mathrm{AU}(\mathrm{D})$ & $\mathrm{AA}(\mathrm{D})$ & $\mathrm{UU}(\mathrm{SD})$ & $\mathrm{UU}(\mathrm{SD})$ & $\mathrm{UU}(\mathrm{SD})$ & SD & 42 & 46 & 44 \\
\hline \multicolumn{6}{|c|}{ Mean Value } & & 45.9 & 46 & 45.95 \\
\hline
\end{tabular}

PCOS patient's and for controls $0.25 \%$, the frequency of total number of Trinucleated cells per 500 cells (mean \pm SD) is 5.5 \pm 6.85 is in PCOS patient's and for controls it is $1.25 \pm 2.5$. The percentage of fragmented nucleus was $0.10 \%$ in PCOS patient's and for controls $0 \%$, the frequency of total number of fragmented nucleus per 500 cells was (mean $\pm \mathrm{SD}$ ) $0.5 \pm 1.58$ in PCOS patient's and for controls $0.00 \pm 0.00$. The percentage of karyolysed nucleus was $30.50 \%$ in PCOS patient's and for controls $7.25 \%$, the frequency of total number of karyolysed nucleus per 500 cells was (mean \pm SD) $152.4 \pm 56.35$ in PCOS patient's and for controls $36.25 \pm 36.82$. The percentage of overall aberrations was found to be $39.25 \%$ in PCOS patient's and for controls $17 \%$. The frequency of total number of aberrations in PCOS patients was (mean \pm SD) 195.9 \pm 55.31 and for controls it is $85 \pm 57.88$. The percentage and frequency of Binucleated cells, frequency of micronuclei in cells, frequency of Trinucleated cells and frequency of fragmented nucleus and frequency of karyolysed nucleus are presented in Table 3A and Figure 3. The statistical analysis of the Buccal cell abnormaliteis observed in the
Patient and control samples were presented in Table 3B.

\section{Cytogenetic analysis}

Cytogenetic analysis was performed in 10 PCOS patients with 4 cases of age and sex matched controls, the results were presented in Table 4A and 4B. G banded Karyotyping analysis revealed 46, XX karyotype in all the 10 PCOS patients and 4 controls. In chromosome aberration analysis of PCOS patients, we have observed different types of chromosome aberrations like chromosome breaks as well chromatid breaks. The total chromosome aberrations in controls were found 4 out of 200 metaphases, in which percentage of aberrations were $2.0 \%$ and the frequency of total aberration is $1 \pm 0$ (mean and SD) (Figure 4A). In PCOS patients the total number of chromosome aberration is 15 out of 500 metaphases, in which percentage of chromosome aberration is $3 \%$ and the frequency of total chromosome aberrations is $1.5 \pm 1.78$. The percentage and frequency of chromosome aberrations were significantly higher in PCOS patients than in controls (Figure 4B). Mean values and standard deviations were 
Table 2B. Frequency of Patterns Observed in Controls and PCOS Patients

\begin{tabular}{|c|c|c|c|c|c|c|c|c|c|c|c|c|c|c|c|}
\hline \multirow[b]{2}{*}{ Patterns } & \multicolumn{7}{|c|}{ Controls } & \multirow[b]{2}{*}{ Patterns } & \multicolumn{7}{|c|}{ PCOS Patients } \\
\hline & Thumbs & Index & Middle & Ring & Little & Total & $\%$ & & Thumbs & Index & Middle & Ring & Little & Total & $\%$ \\
\hline$\overline{\mathrm{AA}}$ & 1 & 1 & 0 & 0 & 0 & 2 & 10 & $\mathrm{AA}$ & 3 & 2 & 1 & 1 & 1 & 8 & 16 \\
\hline AR & 0 & 0 & 0 & 0 & 0 & 0 & 0 & $\mathrm{AR}$ & 0 & 0 & 0 & 0 & 0 & 0 & 0 \\
\hline $\mathrm{AU}$ & 1 & 0 & 2 & 0 & 0 & 3 & 15 & $\mathrm{AU}$ & 2 & 1 & 0 & 1 & 0 & 4 & 8 \\
\hline AW & 0 & 0 & 0 & 0 & 0 & 0 & 0 & AW & 0 & 0 & 0 & 0 & 1 & 1 & 2 \\
\hline RA & 0 & 0 & 0 & 0 & 0 & 0 & 0 & RA & 0 & 0 & 0 & 0 & 0 & 0 & 0 \\
\hline RR & 0 & 0 & 0 & 0 & 0 & 0 & 0 & $\mathrm{RR}$ & 0 & 0 & 0 & 0 & 0 & 0 & 0 \\
\hline RU & 0 & 0 & 1 & 0 & 0 & 1 & 5 & RU & 0 & 0 & 0 & 0 & 0 & 0 & 0 \\
\hline RW & 0 & 0 & 0 & 0 & 0 & 0 & 0 & RW & 0 & 1 & 0 & 0 & 0 & 1 & 2 \\
\hline UA & 0 & 1 & 0 & 0 & 0 & 1 & 5 & UA & 0 & 1 & 0 & 0 & 0 & 1 & 2 \\
\hline UR & 0 & 0 & 0 & 0 & 0 & 0 & 0 & UR & 0 & 0 & 0 & 0 & 0 & 0 & 0 \\
\hline UU & 0 & 1 & 0 & 1 & 0 & 4 & 20 & UU & 2 & 1 & 7 & 3 & 6 & 19 & 38 \\
\hline UW & 0 & 0 & 0 & 0 & 0 & 0 & 0 & UW & 1 & 1 & 0 & 1 & 0 & 3 & 6 \\
\hline WA & 0 & 0 & 0 & 1 & & 1 & 5 & WA & 0 & 0 & 0 & 0 & 0 & 0 & 0 \\
\hline WR & 0 & 0 & 0 & 0 & 0 & 0 & 0 & WR & 0 & 0 & 0 & 0 & 0 & 0 & 0 \\
\hline WU & 0 & 0 & 0 & 0 & 0 & 2 & 10 & WU & 0 & 2 & 2 & 3 & 2 & 9 & 18 \\
\hline WW & 2 & 1 & 1 & 2 & 0 & 6 & 30 & WW & 2 & 1 & 0 & 1 & 0 & 4 & 8 \\
\hline
\end{tabular}

AA: Arches Arches, AR: Arches Radial, AU: Arches Ulnar, AW: Arches Whorls, RA: Radial Arches, RR: Radial Radial, RU: Radial Ulnar, RW: Radial Whorls, UA: Ulnar Arches, UR: Ulnar Radial, UU: Ulnar Ulnar, UW: Ulnar Whorls, WA: Whorls Arches, WR: Whorls Radial, WU: Whorls Ulnar, WW: Whorls Whorls, D: Dominant, SD: Semidominat, RE: Recessive; Parameters followed to conclude the inheritance patterns; Whorls on both thumbs $(\mathrm{WW})=$ Semidominant. (ii) Ulnar loops on both thumbs (UU) $=$ Semidominant. (iii) 1 Ulnar and 1 whorls on each thumbs (UW) $=$ Semidominant. (iv) Arches on any finger except ring and little finger (AA), (AU), (AR), (AW), (UA), (RA), (WA) = Dominant. (v) Radial loops on ring and little finger (RW), (RA), (RR), (RU), (WR), (UR (AR) = Recessive. (vi) Radial loops on all fingers except ring and little finger (RW), (RA), (RR),(RU),(WR),(UR (AR)= Dominant. (vii) Whorls on all fingers except for an ulnar loop (WU) on middle finger (WA) (WU), (WR) (UW) $($ AW) $($ RW) $=$ Dominant. (viii) Whorls on all fingers except thumbs, ring and little finger (WA) (WU), (WR) (UW) (AW) (RW) = Dominant. (ix) Whorls on both ring finger (WW) = Semidominant. (x) Ulnar loops on both ring finger (UU) = Semidominant. (xi) 1 Ulnar and 1 whorls on each ring finger $(\mathrm{UW})=$ Semidominant

Table 3A. Statistical Analysis of the Buccal Cell abnormaliteis observed in the Patient and Control Samples

\begin{tabular}{|c|c|c|c|c|c|c|c|c|c|}
\hline $\begin{array}{l}\text { Patients } \\
\text { Code }\end{array}$ & $\begin{array}{c}\text { No of } \\
\text { cell } \\
\text { scored }\end{array}$ & $\begin{array}{l}\text { Frequency of } \\
\text { MN Cells }\end{array}$ & $\begin{array}{c}\text { Frequency } \\
\text { of } \mathrm{BN} \\
\text { cells }\end{array}$ & $\begin{array}{c}\text { Frequency } \\
\text { of Mni } \\
\text { Cells }\end{array}$ & $\begin{array}{c}\text { Frequency } \\
\text { of cells } \\
\text { with Tri } \\
\text { nucleated }\end{array}$ & $\begin{array}{l}\text { Frequency } \\
\text { of } \\
\text { fragmented } \\
\text { nucleus }\end{array}$ & $\begin{array}{l}\text { Frequency } \\
\text { of } \\
\text { karyolysis } \\
\text { nucleus }\end{array}$ & $\begin{array}{l}\text { Total no. of } \\
\text { aberrations }\end{array}$ & $\begin{array}{c}\% \text { of } \\
\text { aberration }\end{array}$ \\
\hline PCOS 01 & 500 & 420 & 15 & 5 & 0 & 0 & 60 & 80 & 16 \\
\hline PCOS 02 & 500 & 301 & 55 & 0 & 0 & 0 & 144 & 199 & 39.8 \\
\hline PCOS 03 & 500 & 305 & 50 & 0 & 10 & 0 & 135 & 195 & 39 \\
\hline PCOS 04 & 500 & 250 & 10 & 0 & 0 & 0 & 240 & 250 & 50 \\
\hline PCOS 05 & 500 & 335 & 50 & 0 & 20 & 0 & 95 & 165 & 33 \\
\hline PCOS 06 & 500 & 220 & 30 & 0 & 5 & 0 & 245 & 280 & 56 \\
\hline PCOS 07 & 500 & 310 & 25 & 0 & 10 & 5 & 150 & 190 & 38 \\
\hline PCOS 08 & 500 & 345 & 5 & 0 & 0 & 0 & 150 & 155 & 31 \\
\hline PCOS 09 & 500 & 275 & 55 & 0 & 10 & 0 & 160 & 225 & 45 \\
\hline PCOS 10 & 500 & 280 & 75 & 0 & 0 & 0 & 145 & 220 & 44 \\
\hline Total & 5000 & 3041 & 370 & 5 & 55 & 5 & 1524 & 1959 & 391.8 \\
\hline $\begin{array}{l}\text { Mean } \\
\pm \text { SD }\end{array}$ & & $304.1 \pm 55.3$ & $37 \pm 23.24$ & $0.5 \pm 1.58$ & $5.5 \pm 6.85$ & $0.5 \pm 1.58$ & $152.4 \pm 56.35$ & $195.9 \pm 55.31$ & $3.9 \pm 11.06$ \\
\hline \multicolumn{10}{|c|}{ Statistical Analysis of the Buccal Cell Observed in the Control } \\
\hline Con01 & 500 & 440 & 30 & 0 & 0 & 0 & 30 & 60 & 12 \\
\hline Con02 & 500 & 425 & 70 & 0 & 5 & 0 & 10 & 85 & 17 \\
\hline Con03 & 500 & 335 & 75 & 0 & 0 & 0 & 90 & 165 & 33 \\
\hline Con04 & 500 & 470 & 10 & 5 & 0 & 0 & 15 & 30 & 6 \\
\hline Total & 2000 & 1670 & 185 & 5 & 5 & 0 & 145 & 340 & 13.6 \\
\hline $\begin{array}{l}\text { Mean } \\
\pm \text { SD }\end{array}$ & & $417.5 \pm 58.09$ & $46 \pm 31.45$ & $1.25 \pm 2.5$ & $1.25 \pm 2.5$ & $0.00 \pm 0.00$ & $36.25 \pm 36.82$ & $85 \pm 57.8$ & $1.78 \pm 11.58$ \\
\hline
\end{tabular}

\footnotetext{
*MN=Mon nucleated, $\mathrm{BN}=\mathrm{Bi}$ nucleated, $\mathrm{Mni}=$ Micro Nuclei
} 
Multi-Parameter Approach for Evaluation of Genomic Instability in the Polycystic Ovary Syndrome

Table 3B. Statistical Analysis of the Buccal Cell Abnormaliteis Observed in the Patient and Control Samples

\begin{tabular}{|c|c|c|c|c|}
\hline \multirow[b]{2}{*}{ BMCyt Assay variables } & \multicolumn{2}{|c|}{ Controls } & \multicolumn{2}{|c|}{ Patient } \\
\hline & percentage & Mean \pm SD & percentage & Mean \pm SD \\
\hline Bi-nucleated & $9.25 \%$ & $46 \pm 31.45$ & $7.41 \%$ & $37 \pm 23.24$ \\
\hline Micronuclei & $0.25 \%$ & $1.25 \pm 2.5$ & $0.10 \%$ & $0.5 \pm 1.58$ \\
\hline Tri nucleated & $0.25 \%$ & $1.25 \pm 2.5$ & $1.10 \%$ & $5.5 \pm 6.85$ \\
\hline Fragmented nucleus & $0 \%$ & $00 \pm 00$ & $0.10 \%$ & $0.5 \pm 1.58$ \\
\hline Karyolysed nucleus & $7.25 \%$ & $36.25 \pm 36.82$ & $30.50 \%$ & $152.4 \pm 56.35$ \\
\hline Total no of aberrations & $17 \%$ & $85 \pm 57.88$ & 39.21 & $195.9 \pm 55.31$ \\
\hline
\end{tabular}

Table 4. A).Cytogenetic Analysis of PCOS Patients; B) Cytogenetic Analysis of Control Samples

\begin{tabular}{|c|c|c|c|c|c|c|c|c|c|}
\hline \multirow[b]{2}{*}{ Patients Code } & \multicolumn{8}{|c|}{ Chromosome Aberrations } & \multirow[b]{2}{*}{$\begin{array}{c}\text { No. of Abs } \\
\text { Per Cell }\end{array}$} \\
\hline & Karyotype & $\begin{array}{c}\text { Tt. No.of } \\
\text { Cells scored }\end{array}$ & Ch. Bks. & Chd. Bks. & Dic.ch & Rg.Ch. & $\begin{array}{l}\text { Tt. No. of } \\
\text { Ch Abs }\end{array}$ & $\begin{array}{c}\% \text { of } \\
\text { Ch. Abs }\end{array}$ & \\
\hline \multicolumn{10}{|c|}{ A. Cytogenetic analysis of PCOS patients } \\
\hline PCOS 01 & $46, X X$ & 50 & 0 & 0 & 0 & 0 & 0 & 0 & 0 \\
\hline PCOS 02 & $46, X X$ & 50 & 2 & 2 & 0 & 0 & 4 & 8 & 0.08 \\
\hline PCOS 03 & $46, X X$ & 50 & 2 & 1 & 0 & 1 & 4 & 8 & 0.08 \\
\hline PCOS 04 & $44 X X$ & 50 & 0 & 0 & 0 & 0 & 0 & 0 & 0 \\
\hline PCOS 05 & $46, X X$ & 50 & 0 & 0 & 0 & 0 & 0 & 0 & 0 \\
\hline PCOS 06 & $46, X X$ & 50 & 1 & 0 & 0 & 0 & 1 & 2 & 0.02 \\
\hline PCOS 07 & $46 X X$ & 50 & 0 & 0 & 0 & 0 & 0 & 0 & 0 \\
\hline PCOS 08 & $46, X X$ & 50 & 0 & 0 & 0 & 0 & 0 & 0 & 0 \\
\hline PCOS 09 & $46, X X$ & 50 & 0 & 3 & 0 & 0 & 3 & 6 & 0.06 \\
\hline PCOS 10 & $46, X X$ & 50 & 0 & 3 & 0 & 0 & 3 & 6 & 0.06 \\
\hline TOTAL & & 500 & 5 & 9 & 0 & 1 & 15 & 3 & 0.03 \\
\hline Mean \pm SD & & & $0.5 \pm 0.85$ & $0.9 \pm 1.29$ & 0 & $0.1 \pm 0.32$ & $1.5 \pm 1.78$ & $3 \pm 3.55$ & $0.03 \pm 0.03$ \\
\hline \multicolumn{10}{|c|}{ B. Cytogenetic analysis of control samples } \\
\hline Con01 & $46, \mathrm{XX}$ & 50 & 0 & 1 & 0 & 0 & 1 & 2 & 0.02 \\
\hline Con02 & $46, X X$ & 50 & 1 & 0 & 0 & 0 & 1 & 2 & 0.02 \\
\hline Con03 & $46, X X$ & 50 & 1 & 0 & 0 & 0 & 1 & 2 & 0.02 \\
\hline Con04 & $46, X X$ & 50 & 0 & 1 & 0 & 0 & 1 & 2 & 0.02 \\
\hline Total & & 200 & 2 & 2 & 0 & 0 & 4 & 2 & 0.02 \\
\hline Mean \pm SD & & & $0.5 \pm 0.57$ & $0.5 \pm 0.57$ & $0 \pm 0$ & $0 \pm 0$ & $1 \pm 0$ & $2 \pm 0$ & $0.02 \pm 0$ \\
\hline
\end{tabular}

Tt. No.=Total Number; Ch=Chromosome; Chd: Chromatid; Bks: Breaks; Dic;Dicentric ; RG: Ring; Abs: Aberrations

A

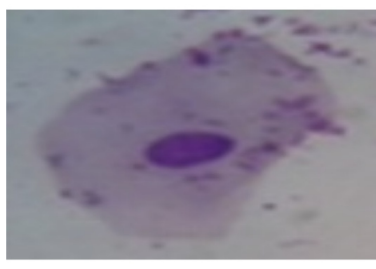

$\mathbf{C}$

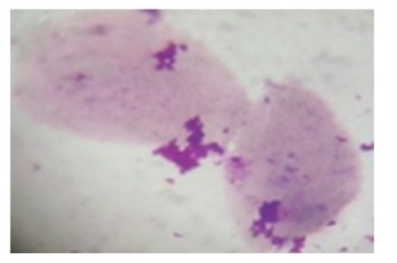

$\mathbf{E}$

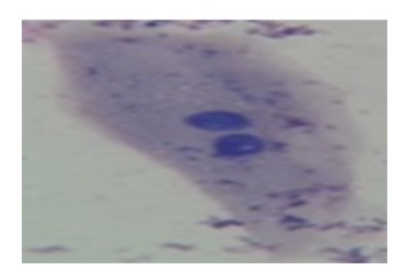

D
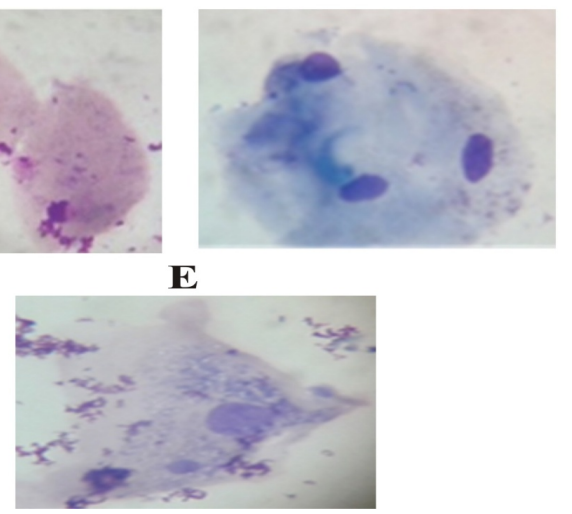

Figure 3. Buccal Cell Micronuclei Assay in PCOS Patients. A-represent mono-nucleated cell ; B- represents bi-nucleated cell; C-represents karyolysed cell; D-represents tri-nucleated cell; E-represents micro-nucleated cell
A

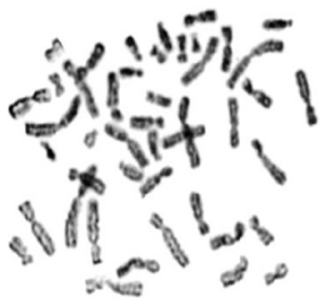

Figure 4. A-Giemsa Stained Chromosome Picture of Control Sample; B-Giemsa Stained Chromosome Picture of PCOS Patient and Arrow Represents the Chromatid Breaks

computed for the scores and it is proved the statistically significance $(\mathrm{P}<0.001)$.

\section{Discussion}

In the present study, we have used multi-parameter analysis techniques including clinical, Dermatoglypics, exfoliated Buccal cell micronuclei and chromosome analysis were carried out to study the genomic instability 
of women with polycystic ovarian syndrome in the region of Vellore, Tamilnadu. The study group included 10 PCOS women and a control group of 4 women. The age in our study was 18 - 28 years. Menstrual disturbances commonly observed in PCOS include Oligomenorrhea, Amenorrhea, and prolonged erratic menstrual bleeding (Farquhar, 2007). Among the entire patient group we have observed that they have irregular periods with little or Medium Acne, but we did not observe any Diabetic, Cardio or Acanthosis Nigricans symptoms. Approximately $85 \%-90 \%$ of women with Oligomenorrhea have PCOS while $30 \%-40 \%$ of women with amenorrhea will have PCOS (Hart, 2007).More than $80 \%$ of women presenting with symptoms of androgen excess have PCOS (Azziz et al., 2004). In our study we have observed the mean value of total testosterone level was $23.6 \mathrm{nmol} / \mathrm{L}$ and total Hirsutism score from 12-24 in PCOS patients. (Elif Yesilada et al.,2006) also reported that they have observed the average value of total testosterone level was $24 \mathrm{nmol} / \mathrm{L}$ and a total Hirsutism score of 4 in healthy control subjects and a total score of 19.5 in PCOS patients. Hirsutism is a common clinical presentation of Hyperandrogenism occurring in up to $70 \%$ of women with PCOS (Fauser et al., 2012). We could find facial acne in $70 \%$ patients. Study has reported that approximately $15 \%-30 \%$ of adult women with PCOS present with acne (Wijeyaratne et al., 2002; Azziz et al., 2004). Some experts recommend that women presenting with acne be asked about their menstrual history and be evaluated for other signs of Hyperandrogenism (Lowenstein, 2006). A polycystic ovary defined as the presence of at least 10 subcapsular follicular cysts, each measures $2-8 \mathrm{~mm}$ in diameter and arranged around or within thickened ovarian stroma and is diagnosed by pelvic ultrasonography (Adams et al., 1985). This study we have observed the 7-12 subcapsular follicular cysts, each measure $2-8 \mathrm{~mm}$ in diameter. Obesity is the often characteristics of PCOS. The prevalence of insulin resistance in PCOS ranges from 50\%-70\% and occurs independently of obesity (Dunaif et al., 1989). In this study we did not observed obesity and insulin resistance in PCOS patients, may be because of small sample size.

Dermatoglyphics has been considered as a growing science with an immense practical value and it has been emphasized as one of the diagnostic tool which aids the Cytogeneticist to look for specific abnormalities and identification of abnormal chromosomes. In the present study, we found increase in mean value $\left(45.9^{\circ}\right)$ of ATD angle of right and left hand of PCOS patients. In one of study (Nikha et al., 2013) reported that increase in the ATD angle value $\left(44.3^{\circ}\right)$ in obese females. In one of the study they have observed increased frequency of total radial loops and total whorls and decreased frequency of total ulnar loops and total arches (Shweta et al., 2014). This study we have observed increased frequency (38\%) of Ulnar loops on both fingers (UU), (18\%) Whorls on right finger and Ulnar loop on left finger (WU) and (16\%) Arches on right and left finger (AA) were observed. Among the frequency of finger print patterns, loops seemed to be of higher frequency in controls as well as in amenorrheic subjects (Meenakshi et al., 2006). This increase in the loop pattern has also been reported by Forbes 4 and (Mutalik et al., 2003) in their study on gonadal dysgenesis and amenorrhea respectively. But in this study we observed (30\%) Whorls on right and left finger (WW), (20\%) Ulnar loops on both fingers (UU) and $(15 \%)$ Arches on left finger and Ulnar loops on right finger (AU).

Features which could be applied as markers for PCOS patients are the presence of Ulnar loops in Middle and Little fingers of right and left hand. (Meenakshi $S$, 2006) reported that the features which could be applied as markers for amenorrhea are the presence of arch pattern in the 2 nd left finger, loop pattern on the 5th right finger. The present study has emphasized the application of Dermatoglyphics as one of the diagnosis tools for referral of PCOS patients for Ultrasound scan. In the present study we found reduction in frequency of Whorls on right and left finger when compare with control subjects. Reduction in frequency Total Loops (TL) and total arches (TA) were observed in primary amenorhoea cases (Meenakshi S, 2006). Some authors found increased ulnar loops (6 of 10 cases) when Dermatoglyphic study was carried out in ten female patients with sex chromatin abnormalities and genital tract anomalies complaining of primary amenorrhoea (Mutalik et al., 1968). We also found increased ulnar loops when Dermatoglyphic analysis on 10 PCOS cases. Some authors found increased frequency of ulnar loops on first finger of right hand when study was carried out in 52 women with the Ullrich-Turner syndrome (Otto PA and Otto PG, 1980). Another author found higher frequency of loops in both controls and primary amenorrhoea cases frequency was especially higher in subjects with abnormal karyotype (Meenakshi et al., 2006). Dermatoglyphics may be a useful screening method to identify the patients at risk and referral of such individuals for ultrasound scan so that a watch may be kept for the early onset of symptoms of polycystic ovarian syndrome.

The Buccal Micronucleus Cytome assay in exfoliated Buccal cells is utilized as biomarkers for DNA damage, cell death and basal cell frequency. It offers great opportunity to evaluate Genotoxicity by the way of quantifying mean frequencies of Micronuclei, Binucleated cell, broken egg, karyolysis, karyorrhexis, pycknosis and condensed chromatin. This assay is sensitive, minimally invasive, simple, cheap, easy and fast (Yadav et al., 2015; Jaggi et al., 2015).

According to (Holland et al., 2008) about $90 \%$ of all cancers are derived from epithelial cells. Since more than $90 \%$ of all human cancers are of epithelial origin, $\mathrm{MN}$ assay with Buccal epithelial cells is the most suitable biomonitoring approach for the detection of increased cancer risk in humans. Buccal cells have limited DNA repair capacity relative to peripheral blood lymphocytes, and therefore, may more accurately reflect age-related genomic instability event in epithelial tissue (Dhillon et al., 2004). A significant increase in the frequencies of $\mathrm{MN}$ was observed in exfoliated Buccal cells of polycystic ovarian syndrome patients (Nersesyan and Chobanyan, 2010). In this study we found a insignificant frequencies of $\mathrm{MN}$ was observed in exfoliated buccal cells of polycystic ovarian 
syndrome patients, may be because of very small sample size. Karyolysis represent an advanced stage of necrosis and apoptosis (Majno and Joris, 1995). In our study we found significant increases in frequencies of Karyolysed nucleus in exfoliated Buccal cells PCOS patients. Micronuclei in exfoliated buccal cells reflect Genotoxic events that occurred in the dividing basal layer 1-3 weeks earlier (Stich et al., 1983, 1984). The frequency of occurrence of $\mathrm{MNi}$ is a measure of chromosome breakage in early cell divisions, and the number of micronuclei is known to increase with carcinogenic stimuli, long before the development of clinical symptoms (Stich et al., 1984). Genetic instability can have very serious consequences for PCOS patients because of established correlations of increased levels of $\mathrm{MN}$ and chromosomal aberrations with cancer incidence (Bonassi et al., 2005).

(Andrea et al., 2001) stated that family studies have indicated a genetic susceptibility to PCOS. Another group studied chromosomal aberrations level in lymphocytes of 15 PCOS patients from Armenia and found 2.25-fold significant increase of this parameter compared with healthy females (Nersesyan et al., 2006). In one of the previous study on beedi workers, we observed 3.63-fold significant increase of chromosomal aberrations when compared with healthy control group (Rajiv et al., 2013). In this study we found significant increase in frequency of chromosome aberration (CA) in PCOS patients when compare with control group. (Nersesyan et al., 2006) concluded that females with PCOS have increased chromosomal aberrations (CAs) level in lymphocytes which is a sign of genetic instability. There is a hypothesis that micronuclei and chromosomal aberrations could have a predictive value for cancer and therefore substitute chromosomal aberrations as cancer risk biomarkers (Aardema et al., 1998).

In conclusion, in this study we have used multiparameter approach to assess the Genomic instability polycystic ovarian syndrome. In clinical analysis we have observed the mean value of total Testosterone level was $23.6 \mathrm{nmol} / \mathrm{L}$, total Hirsutism score was from 12-24, facial Acne in 70\% patients and 7-12 subcapsular follicular cysts, each measure $2-8 \mathrm{~mm}$ in diameter. In Dermatoglypics analysis we observed increases in mean value $\left(45.9^{\circ}\right)$ of ATD angle when compare with control group and also found increased frequency (38\%) of Ulnar loops on both fingers (UU), (18\%) Whorls on right finger and Ulnar loop on left finger (WU) and (16\%) Arches on right and left finger (AA) were observed of right and left hand of PCOS patients when compare with control subjects. Features which could be applied as markers for PCOS patients are the presence of Ulnar loops in Middle and Little fingers of right and left hand. In the present study we found reduction in frequency of Whorls on right and left finger when compare with control subjects. The Buccal Micronucleus Cytome assay in exfoliated Buccal cell, we found decrease in frequencies of micronuclei and significant increases in frequencies of Karyolysed nucleus were observed in polycystic ovarian syndrome patients. Chromosome aberration analysis revealed a significant increase in frequency of chromosome aberration (CA) in PCOS patients when compare with age and sex matched control group. From this present work it can be concluded to some extent that non-invasive technique like Dermatoglypics analysis and Buccal Micronucleus Cytome assay in exfoliated Buccal cell can also be effective in finding a biomarker for polycystic ovarian syndrome. PCOS have increased chromosomal aberrations (CAs) level in lymphocytes which is a sign of genetic instability. Our findings suggest that there is genetic instability in peripheral blood lymphocytes of women with polycystic ovarian syndrome. There is a hypothesis that micronuclei and chromosomal aberrations could have a predictive value for cancer and therefore substitute chromosomal aberrations as cancer risk biomarkers (Aardema et al., 1998). Women with PCOS have a nearly 3 times increased risk for developing endometrial cancer, the association between PCOS and endometrial cancer involves prolonged endometrial exposure to unopposed estrogen by cyclic progesterone due to anovulation (Tokmak et al., 2013).

\section{Acknowledgements}

The authors are indebted to patients for providing us with blood samples. The authors would also like to thank the management of VIT University for providing the facilities to carry out this work. The author Nishu is grateful to VIT University for providing the financial assistance during this tenure.

\section{References}

Aardema MJ, Albertini S, Arni P, et al (1998). Aneuploidy: A report of an ECETOC task force. Mutat Res, 410, 3-79.

Adams J, Polson DW, Abdulwahid N, et al (1985). Multifollicular ovaries: clinical and endocrine features and response to pulsatile gonadotropin releasing hormone. Lancet, 2, 1375-9.

Andrea, Dunaif, Abraham Thomas (2001). Current concepts in the polycystic ovary syndrome. Annu Rev Med, 52, 401-19.

Azziz R, Sanchez L, Knochenhauer ES, et al (2004). Androgen excess in women: experience with over 1000 consecutive patients. J Clin Endocrinol Metab, 89, 453-462.

Bhardwaj N, Bhardwaj P, Tewari V, Siddiqui MS (2015) . Dermatoglyphic analysis of fingertip and palmer print patterns of obese children. Int J Med Sci Public Health, 4, 946-9.

Bonassi S, Ugolini D, Kirsch-Volders M, et al (2005). Human population studies with cytogenetic biomarkers: review of the literature and future prospectives. Environ Mol Mutagen, 45, 258-270.

Cummins H and Midlo C (1961). Fingerprints, Palms and Soles. An introduction to dermatoglyphics. New York: Dover Publ, 1961.

Dhillon VS, Aslam M, Husain SA (2004). The contribution of genetic and epigenetic changes in granulosa cell tumors of ovarian origin. Clin Cancer Res, 10,5537-45.

Diamanti-Kandarakis E, Argyrakopoulou G, Economou F, Kandaraki E, Koutsilieris M (2008). Defects in insulin signaling pathways in ovarian steroidogenesis and other tissues in polycystic ovary syndrome (PCOS). $J$ Steroid Biochem Mol Biol, 109, 242-6.

Dunaif A (1997). Insulin resistance and the polycystic ovary syndrome: mechanism and implications for pathogenesis. Endocr Rev, 18, 774-800.

Dunaif A, Sega KR, Futterweit W, Dobrjansky A (1989). 
Nishu Sekar et al

Profound peripheral insulin resistance independent of obesity in polycystic ovary syndrome. Diabetes, 38, 1165-74.

Elif Yesilada, Ibrahim Sahin, Hamdi Ozcan, Ibrahim Halil Yıldırım, Saim Yologlu and Cagatay Taskapan (2006). Increased micronucleus frequencies in peripheral blood lymphocytes in women with polycystic ovary syndrome. Eur J Endocrinol, 154, 563-8.

Farquhar C (2007). Introduction and history of polycystic ovary syndrome. In: Kovacs G, Norman R, editors.Polycystic Ovary Syndrome. 2nd ed. Cambridge, UK: Cambridge University Press, 4-24.

Fauser B, Tarlatzis B, Rebar R, et al (2012). Consensus on women's health aspects of polycystic ovary syndrome (PCOS): the Amsterdam ESHRE/ASRM-Sponsored 3rd PCOS Consensus Workshop Group. Fertil Steril, 97, 28-38.

Ferriman D, Gallwey JD (1961). Clinical assessment of body hair in women. J Clin Endocrinol Meta, 21, 1440-7.

Hart R. Definitions ( 2007). Prevalence and symptoms of polycystic ovaries and the polycystic ovary syndrome. In: Allahbadia GN, Agrawal R, editors. Polycystic Ovary Syndrome. Kent, UK, Anshan, Ltd,15-26.

Holland N, Bolognesi C, Kirsch-Volders M, et al (2008). The micronucleus assay in human buccal cells as a tool for biomonitoring DNA damage: the HUMN project perspective on current status and knowledge gaps. Mutat Res, 659, 93-108.

Hungerford DA (1965). Leucocytes cultured from small inocula of whole blood and the preparation of metaphase chromosomes by treatment with hypotonic KCl. Stain Technol, 40, 333-8.

Lengauer C, Kinzler, KW, Vogelstein B (1998). Genetic instabilities in human cancers, Nature, 396, 643-9.

Lowenstein E (2006). Diagnosis and management of the dermatologic manifestations of the polycystic ovary syndrome. Dermatol Ther, 19, 210-23.

Majno G, Joris I (1995). Apoptosis, oncosis, and necrosis. An overview of cell death. Am J Pathol, 146, 3-15.

Meenakshi S, Balasubramanyam V, Sayee Rajangam (2006). Dermatoglyphics in amenorrhea qualitative analysis. $J$ Obstet Gynecol India, 56, 250-4.

Mutalik GS, Lokhandwala VA, Anjeneyulu R (1968). Dermatoglyphical findings in primary amenorrhoea.J Obstet Gynecol India, 18, 738-43.

Nersesyan A, Martirosyan A, Parsadanyan G, Zalinyan G (2006). Chromosomal aberrations level in peripheral blood lymphocytes of women with polycystic ovary syndrome. $J$ BUON, 11, 477-480.

Nersesyan A, Chobanyan N (2010). Micronuclei and other nuclear anomalies levels in exfoliated buccal cells and DNA damage in leukocytes of patients with polycystic ovary syndrome. J BUON, 15, 337-339.

Nina Holland, Claudia Bolognesi, Micheline Kirsch-Volders, et al (2008). The micronucleus assay in human buccal cells as a tool for biomonitoring DNA damage: The human project perspective on current status and knowledge gap. Mutat Res, 659, 93-108.

Otto PA, Otto PG (1980). The importance of a'-d ridge count in dermatoglyphic diagnosis of the ullrich-turner syndrome. Am J Med Genet, 6, 145-5.

Poretsky L, Cataldo N, Rosenwaks Z, Guidice L (1999). The insulin-4 related ovarian regulatory system in health and disease. Endocr Rev, 20, 532-82.

Schaumann B, Alter M (1976). Dermatoglyphics in medical disorders. New York. Springer-Verlag.

Shweta Talhar S, Bharat Sontakke R, et al (2014). Dermatoglyphics and karyotype analysis in primary amenorrhoea. A J Clin Diagn Re, 12, 13-16.
Simpson JL (1992). Elucidating the genetics of polycystic ovary syndrome. In Dunaif, A., Givens, J.R., Haseltine, F.P. and Merriam, G.R.(eds), Polycystic ovary syndrome. Blackwell Scientific, Oxford, 59-77.

Stich HF, San RH, Rosin MP (1983). Adaptation of the DNArepair and micronucleus tests to human cell suspensions and exfoliated cells. Ann N Y Acad Sci, 407, 93-105.

Stich HF, Rosin MP, Vallejera MO (1984). Reduction with vitamin A and beta-carotene administration of proportion of micronucleated buccal mucosal cells in Asian betal nut and tobacco chewers. Lancet, 1, 1204-6.

Sundaramoorthy R, Srinivasan V, Gujar J, et al (2013). Clinical, cytogenetic and CYP1A1 exon-1 gene mutation analysis of beedi workers in vellore region, Tamil Nadu. Asian Pac J Cancer Prev, 14, 7555-60.

Tokmak A, Kokanali MK, Guzel AI, et al (2013). Polycystic ovary syndrome and risk of endometrial cancer, a minireview. Asian Pac J Cancer Prev, 15, 7011-14.

Unluhizarci K, Kaltsas G, Kelestimur F (2012). Non polycystic ovary syndrome-related endocrine disorders associated with hirsutism. Eur J Clin Invest, 42, 86-94.

Wijeyaratne CN, Balen AH, Barth JH, Belchetz PE (2002). Clinical manifestations and insulin resistance (IR) in polycystic ovary syndrome (PCOS) among south Asians and Caucasians: is there a difference?. Clin Endocrinol (Oxf), 57, 343-50.

Yadav AS , Jaggi S (2015). Buccal micronucleus cytome assay- a biomarker of genotoxicity. J Mol Biomark Diagn, 6, 236.

Zhao PL, Zhang QF, Yan LY, et al (2014). Functional investigation on aromatase in endometrial hyperplasia in polycystic ovary syndrome cases. Asian Pac J Cancer Prev, 15, 8975-9. 